Cite this: RSC Advances, 2013, 3, 16345

Received 5th June 2013,

Accepted 16th July 2013

DOI: $10.1039 / c 3 r a 42762 e$

\section{Innovative semi-transparent nanocomposite films presenting photo-switchable behavior and leading to a reduction of the risk of infection under sunlight}

\author{
S. Rtimi, ${ }^{a}$ C. Pulgarin, ${ }^{* a}$ R. Sanjines ${ }^{b}$ and J. Kiwi ${ }^{\star c}$
}

www.rsc.org/advances

Novel sputtered polyethylene- $\mathrm{TiO}_{2}\left(\mathrm{PE}-\mathrm{TiO}_{2}\right)$ thin films induce fast bacterial inactivation with concomitant photo-switchable hydrophobic to hydrophilic transition under light. RF-plasma pretreatments allowed an increased $\mathrm{TiO}_{2}$ loading on $\mathrm{PE}$, favorably affecting the photocatalyst performance. ATR-FTIR spectroscopy shows that the increase in the cell lipid-layer fluidity leads to cell wall scission/bacterial inactivation.

The stable, strong adhesion of $\mathrm{TiO}_{2}$ films to glass, iron plates, textile fabrics and thin polymer films active under solar light irradiation is a subject of timely research involving $\mathrm{TiO}_{2}$ selfcleaning and inactivation properties. ${ }^{1-4}$ Several methods are used to prepare $\mathrm{TiO}_{2}$ thin films, based on sol-gel processing depending on the heat resistant of the selected substrate. Sol-gel processing is the most commercially commonly used method to prepare $\mathrm{TiO}_{2}$ films ${ }^{5}$ but the thickness of the $\mathrm{TiO}_{2}$ films is not reproducible, they are not mechanically stable, and they exhibit low adhesion since they can be wiped off by a cloth or thumb. ${ }^{6-8}$ Polyethylene (PE) is a low cost, inert and mechanically strong thin flexible polymer. For this reason PE has been selected as the support for the semitransparent $\mathrm{TiO}_{2}$ films we report in this study.

The low surface energy of PE leads to poor particle adhesion. For this reason the PE was pretreated by RF and UVC to produce highly functional self-cleaning and anti-bacterial coatings increasing the surface sites able to bind $\mathrm{TiO}_{2}$ nanoparticles. ${ }^{7}$ The plasma pretreatment has been reported to increase the polymer polarity, roughness and hydrophilicity, improving its binding capacity and interfacial adhesion., ${ }^{2,6}$ RF-plasma pretreatment of surfaces enhancing the antibacterial activity has been reported. ${ }^{3-5}$ The RF-plasma pretreatment of PE induces negatively charged functional groups, e.g., carboxylic, percarboxylic, epoxide and peroxide groups by the atomic $\mathrm{O}$, excited $\mathrm{O}$, anionic and cationic $\mathrm{O}$ in the

${ }^{a}$ Ecole Polytechnique Fédérale de Lausanne, EPFL-SB-ISIC-GPAO, Station 6, CH1015, Lausanne, Switzerland. E-mail: cesar.pulgarin@epfl.ch; Fax: +41 (0)21 69356 90; Tel: +41 (0)216934720

${ }^{b}$ Ecole Polytechnique Fédérale de Lausanne, EPFL-SB-IPMC-LNNME, Bat PH, Station 3, CH-1015, Lausanne, Switzerland

${ }^{c}$ Ecole Polytechnique Fédérale de Lausanne, EPFL-SB-ISIC-LPI, Bat Chimie, Station 6, CH1015, Lausanne, Switzerland.E-mail:john.kiwi@epfl.ch gas in the $\mathrm{RF}$ chamber. These $\mathrm{O}$-species interact with the functionalized $-\mathrm{CH}_{2}-\mathrm{CH}_{2}-$ groups of $\mathrm{PE}$ binding $\mathrm{TiO}_{2}$ by electrostatic attraction. Reports by: Sarakinos, et al., ${ }^{9}$ Kelly et al., ${ }^{10}$ Parkin et al., ${ }^{11}$ Foster et al., ${ }^{12}$ Yates, et al., ${ }^{13}$ report the sputtering and CVD deposition of $\mathrm{TiO}_{2}$ on different surfaces.

The objectives of this study are: a) to present RF-plasma pretreated $\mathrm{TiO}_{2}-\mathrm{PE}$ sputtered uniform adherent films showing fast bacterial inactivation kinetics, b) to show light induced hydrophobic to hydrophilic reversible switchable behavior in $\mathrm{PE}-\mathrm{TiO}_{2}$ films and c) to show by ATR-FTIR that the increase in the cell lipid layer fluidity during the loss of cell viability leads to bacterial cellwall scission.

The low density polyethylene (LDPE) consists of highly branched low crystalline semi-transparent film with the formula $\mathrm{H}\left(\mathrm{CH}_{2}-\mathrm{CH}_{2}\right)_{n} \mathrm{H}$. The PE was pretreated in the cavity of the RFplasma unit (Harrick Corp. 13.56 MHz, $100 \mathrm{~W}$ ). ${ }^{3,8}$ The details of both pretreatment methods on C-rich surfaces have been recently described. ${ }^{3-5}$ The $\mathrm{TiO}_{2}$ was sputtered by direct current magnetron sputtering (DC) on polyethylene as reported out of our laboratory. ${ }^{4,8}$ Before sputtering the films, the residual pressure $P_{\mathrm{r}}$ in the sputtering chamber was set to $P_{\mathrm{r}} \leqslant 10^{-4} \mathrm{~Pa}$. The substrate target distance was set at $10 \mathrm{~cm}$. The $\mathrm{TiO}_{2}$ thin films were deposited by reactive DC-magnetron sputtering (DC) in an $\mathrm{O}_{2}$ gas flow from a 5 cm diameter Ti-target 99.99\% pure (Kurt J. Lesker, East Sussex, UK). The current on the Ti target was set at $280 \mathrm{~mA}$, at a power of 128 Watt $(-518 \mathrm{~V})$. The samples of Escherichia coli (E. coli K12) were obtained from the Deutsche Sammlung von Mikroorganismen und Zellkulturen GmbH (DSMZ) ATCC23716, Braunschweig, Germany, to test the antibacterial activity of the $\mathrm{PE}-\mathrm{TiO}_{2}$ sputtered fabrics, and details of the evaluation of $E$. coli during the inactivation process have been recently reported. ${ }^{5,8}$ The photo-induced super-hydrophilic hydrophobic transformation was evaluated on the $\mathrm{PE}-\mathrm{TiO}_{2}$ surface by the sessile drop method on a DataPhysics OCA 35 unit. The ATR-FTIR spectra were measured in a Portmann Instruments AG spectrophotometer equipped with a Specac attachment $\left(45^{\circ}\right.$ one pass diamond crystal). The position of the IR peaks was found by the second derivative of the spectra after Fourier deconvolution. The effective mass of the $\mathrm{TiO}_{2}$ used in the different samples was determined by X-ray fluorescence (XRF) 
Table $1 \mathrm{X}$-ray fluorescence determination (XRF) analyses of $\mathrm{TiO}_{2}$ on PE samples sputtered for 8 min with and without PE-pretreatment

Pretreatment type and time

$\mathrm{PE}-\mathrm{TiO}_{2}$, no pretreatment

$\mathrm{PE}-\mathrm{TiO}_{2}, \mathrm{RF}$ plasma pretreated under vacuum $15 \mathrm{~min}$ (1 torr)

$\mathrm{PE}-\mathrm{TiO}_{2}, \mathrm{RF}$ air plasma pretreated for $15 \mathrm{~min}$
Surface $\mathrm{TiO}_{2}$ wt\%/wt PE

0.0511

0.0815

0.0959 in a PANanalytical PW2400 spectrometer. Table 1 shows the results for the $\mathrm{PE}-\mathrm{TiO}_{2}$ samples sputtered for $8 \mathrm{~min}$ with and without RF-pretreatment.

Fig. 1a shows the $E$. coli inactivation on $\mathrm{PE}-\mathrm{TiO}_{2}$ films under simulated solar light for non-pretreated $\mathrm{TiO}_{2}$ samples sputtered for different times. The sputtering time of 8 min shown in Fig. 5, trace (1) led to the most effective $\mathrm{TiO}_{2}$ loading of $\mathrm{PE}$ and this trace was subjected to statistical analysis. $\mathrm{PE}-\mathrm{TiO}_{2}$ samples sputtered for 1-5 min did not deposit sufficient $\mathrm{TiO}_{2}$ to drive the bacterial inactivation. Samples sputtered for $10 \mathrm{~min}$, Fig. 1a, trace (2), led to a layer thickness $>45 \mathrm{~nm}$. This latter thickness increases the bulk inward diffusion of the photo-induced $\mathrm{TiO}_{2}$ charge carriers responsible for the charge transfer between the $\mathrm{PE}-\mathrm{TiO}_{2}$ and bacteria. ${ }^{14}$ The light dose of the solar simulator used was tuned to $50 \mathrm{~mW} \mathrm{~cm}^{-2}$, for the runs reported in Fig. 1-3.

Fig. 1b, trace (1)shows the fastest bacterial inactivation, within $60 \mathrm{~min}$ for $\mathrm{PE}-\mathrm{TiO}_{2}$ films previously RF-pretreated in air for 15 min and then sputtered for $8 \mathrm{~min}$. RF-pretreatment for $5 \mathrm{~min}$ (Fig. 1b, trace 4) did not induce enough oxygenated functional groups on the PE surface to bond a high amount of $\mathrm{TiO}_{2}$ mediating $E$. coli inactivation. Fig. 1b, traces 2 and 3 show that samples RF-pretreated for 20 and 30 min respectively did not lead

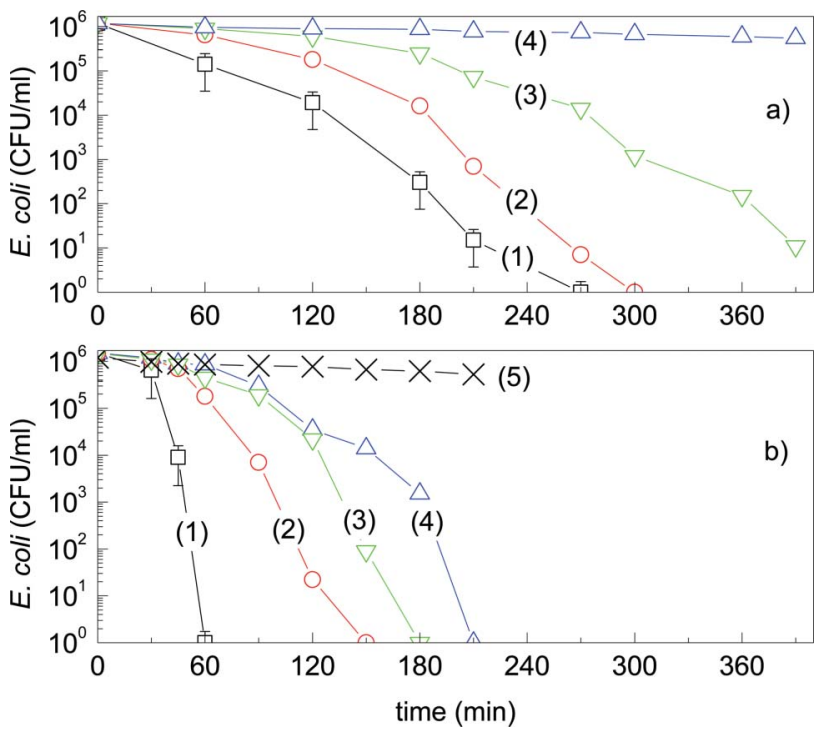

Fig. 1 E. coli inactivation on $\mathrm{TiO}_{2}$ sputtered on $\mathrm{PE}$ for 8 min irradiated with simulated solar light. a) $\mathrm{TiO}_{2}$ sputtered for different times without RF-plasma pretreatment for: (1) $8 \mathrm{~min}$, (2) $10 \mathrm{~min},(3) 5 \mathrm{~min}$ and (4) polyethylene alone, b) $\mathrm{TiO}_{2}$ sputtered for 8 min after RF air plasma pretreatment for: (1) 15 min, (2) 20 min, (3) $30 \mathrm{~min},(4) 5 \mathrm{~min}$ and (5) PE alone RF air pretreated for $15 \mathrm{~min}$. to faster bacterial inactivation kinetics compared to samples RFpretreated only for $15 \mathrm{~min}$. RF-plasma at $100 \mathrm{~W}$ induced a local heating in the PE, breaking intermolecular bonds (H-bonds) and partially segmenting $\mathrm{PE}$ with temperatures $>160{ }^{\circ} \mathrm{C}$ produced during nano- or microseconds and not introducing permanent damage into the PE surface., ${ }^{4,6,8}$

The optical absorption for samples pretreated by RF-plasma and sputtered for 1-3 min lead to transparent $\mathrm{PE}-\mathrm{TiO}_{2}$ films. These films show no significant absorbance and very low antibacterial activity. A decrease of $\sim 5 \%$ or more in optical transmittance has been reported for RF-plasma pretreated PE due to the inherent high refractive index of $\mathrm{TiO}_{2} \cdot{ }^{15} \mathrm{Fig} .2$ illustrates the rate of photo-induced hydrophilicity and the restoration of the hydrophobicity in the dark as a function of " $\cos \theta$ ". According to Young's theory, ${ }^{2,14}$ the "cos $\theta$ " of a liquid droplet on a solid surface is a function of the interfacial energy between the solid and liquid. That bacterial inactivation in the dark did not lead to bacterial inactivation suggests that the hydrophobicity of the nonirradiated $\mathrm{PE}-\mathrm{TiO}_{2}$ films remained stable.

The rate of the hydrophobic to hydrophilic conversion and of the reverse reaction in Fig. $2 \mathrm{a}$ and $2 \mathrm{~b}$ were $2.77 \times 10^{-1} \mathrm{~min}^{-1}$ and $8.71 \times 10^{-3} \mathrm{~min}^{-1}$ respectively. These rates were calculated by integrating " $\cos \theta$ " in the Young's eq. $\cos \theta=c \gamma^{1 / 2}-1$, where $\gamma$ is the surface free energy and $t=\infty$ corresponds to interfacial energy of the hydrophobic surface before irradiation. This surface energy increases upon illumination since the $\mathrm{TiO}_{2}$ surface is transformed into a metastable hydrophilic state decreasing the initial contact angle in Fig. 2a from $121^{\circ}$ to $<5^{\circ}$ after 60 min illumination. The reversible reaction back to the initial state within $24 \mathrm{~h}$ was monitored in Fig. 2b, showing the contact angle increase from $37^{\circ}$ up to $\sim 118^{\circ}$.
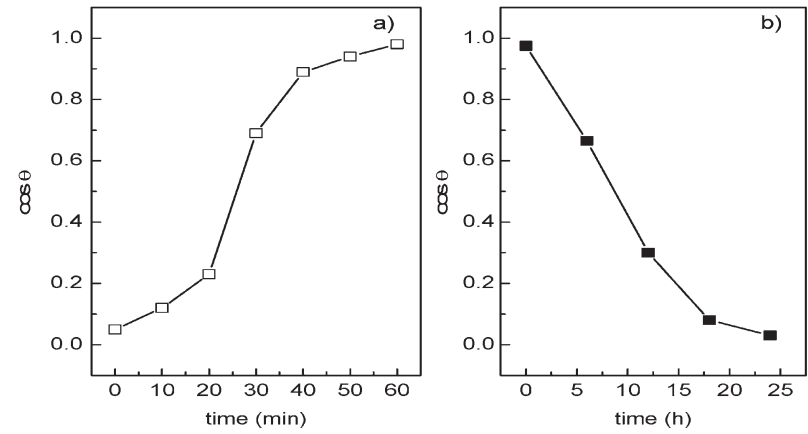

Fig. 2 a) $\cos \theta$ plot of the switchable induced transition of $\mathrm{PE}-\mathrm{TiO}_{2}$ (sputtered for 8 min and RF plasma pretreated for $15 \mathrm{~min}$ ) kinetics under solar simulated irradiation and b) dark reverse reaction kinetics towards the initial state. 

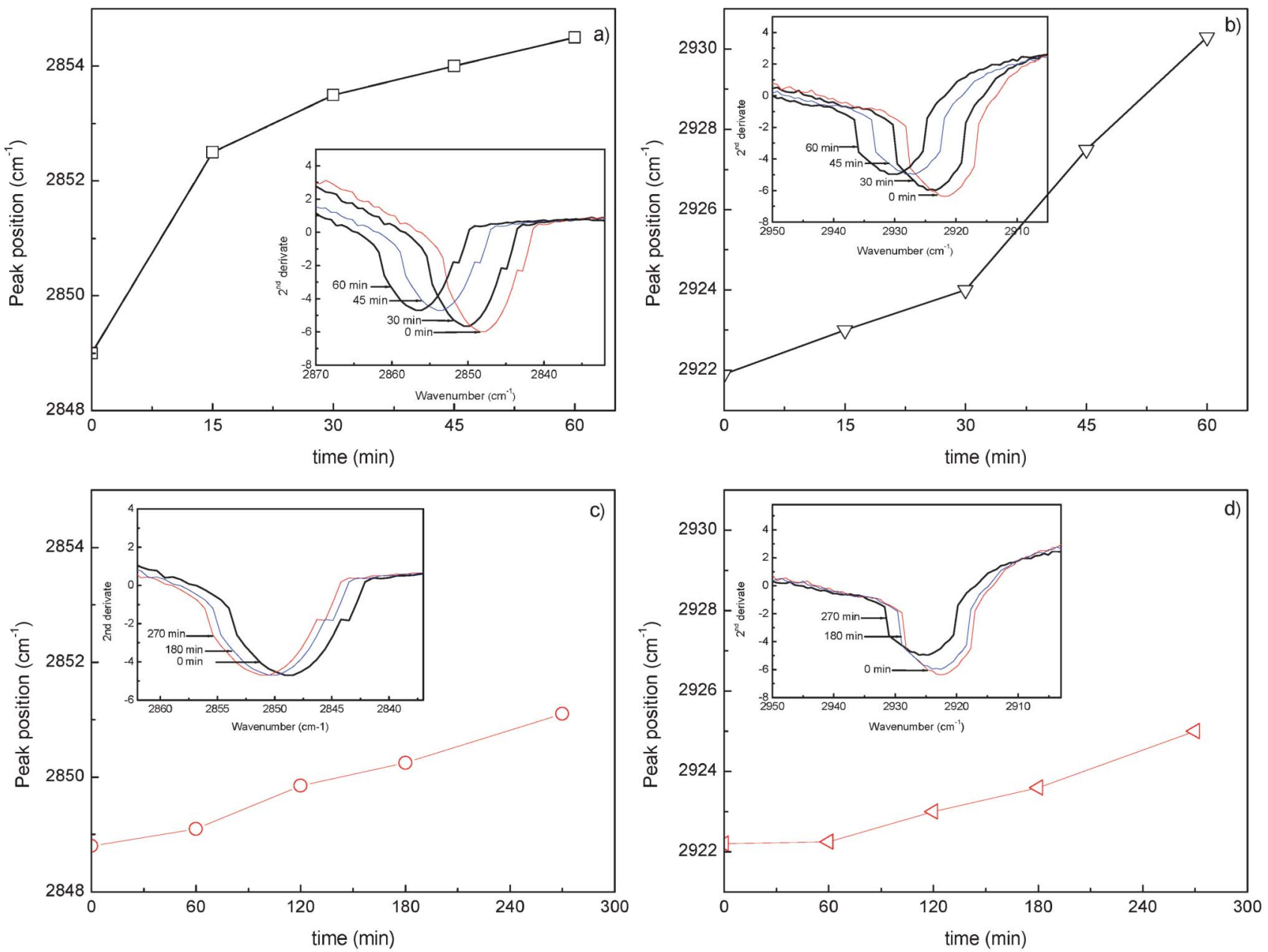

Fig. 3 Change in the second derivative of the ATR-FTIR peaks for the asymmetric $v_{\mathrm{a}}\left(\mathrm{CH}_{2}\right)$ vibrational bands and the symmetric $v_{\mathrm{s}}\left(\mathrm{CH}_{2}\right)$ vibrational bands up to 60 min under solar simulated irradiation for E. coli under light. Fig. $3 \mathrm{a}$ and $3 \mathrm{~b}$ show the IR shifts for PE-TiO $\mathrm{O}_{2}$ samples pretreated with RF plasma for 15 min and sputtered for 8 min. Fig. $3 \mathrm{C}$ and $3 \mathrm{~d}$ show the IR shifts for $\mathrm{PE}-\mathrm{TiO}_{2}$ samples without RF-plasma pretreatment sputtered for $8 \mathrm{~min}$.

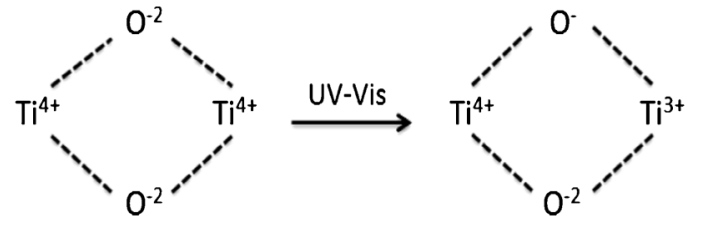

The hydrophobic to super-hydrophilic $\mathrm{TiO}_{2}$ transition activated by UV-vis irradiation induces the metastable $\mathrm{TiO}_{2}$ hydrophilic species shown in eqn (1). The reuse of the $\mathrm{Pe}-\mathrm{TiO}_{2}$ samples during several cycles led to a stable bacterial loss of viability. This means that the RF-plasma pretreatment anchored $\mathrm{TiO}_{2}$ nanoparticles on PE, but did not destroy the PE network. Tennakone et al., ${ }^{16}$ and Ohtani et al., ${ }^{17}$ have shown that $\mathrm{TiO}_{2}$ embedded on the PE surface by sol-gel methods induced PE-surface degradation, limiting its photocatalytic performance. Recently, R. Amal reported reversible photo-switching behavior under light by Ag-nanoparticles. ${ }^{18}$

The photocatalytic peroxidation of the $E$. coli cell wall membrane gives rise to the shift reported in Fig. 3. Fig. 3a shows the shift of the asymmetric methylene peak at $v_{\mathrm{a}}\left(\mathrm{CH}_{2}\right) \mathbf{2 9 2 2 . 2}$ $\mathrm{cm}^{-1}$ and of the symmetric $v_{\mathrm{s}}\left(\mathrm{CH}_{2}\right) 2849.2 \mathrm{~cm}^{-1}$ peak of the cell- wall under light irradiation up to $60 \mathrm{~min}$. The shift was recorded on the sample RF-plasma pretreated for $15 \mathrm{~min}$, and sputtered for $8 \mathrm{~min}$. This shift is important since the $\left(\mathrm{CH}_{2}\right)-$ and $\left(\mathrm{CH}_{3}\right)$ - groups make up $70 \%$ of the cell wall content in the three $E$. coli cell-wall envelopes. The progressive decrease of the asymmetric $v_{\mathrm{a}}$ and $v_{\mathrm{s}}$ symmetric bands is shown in the insert to Fig. 3a and $3 \mathrm{~b}$. As the irradiation progresses, the shift of the asymmetric $v_{\mathrm{a}}\left(\mathrm{CH}_{2}\right)$ and the symmetric $v_{\mathrm{s}}\left(\mathrm{CH}_{2}\right)$ peaks reflects larger intermolecular $\mathrm{C}-\mathrm{H}$ bond distances. ${ }^{19}$ The IR shifts for sputtered $\mathrm{PE}-\mathrm{TiO}_{2}$ films RF-plasma pretreated in Fig. $3 \mathrm{a}$ and $3 \mathrm{~b}$ are seen to be more significant compared to the non-pretreated samples shown in Fig. 3c and 3d under the same experimental conditions. This fact is due to the lower amount of $\mathrm{TiO}_{2}$ on the non RF-pretreated PE leading longer bacteria inactivation times. The shifts shown in Fig. 3 have been assigned to an increase in the cell-wall fluidity during the $E$. coli photocatalyzed inactivation by way of $\mathrm{TiO}_{2}$ dispersions. ${ }^{20,21}$ This suggests that increasing the lipid fluidity induces damage/ permeabilization into the $E$. coli cell wall functional groups. 


\section{Conclusions}

By sputtering methods, uniform and adhesive thin $\mathrm{TiO}_{2}$ semitransparent layers allowing considerable light transmittance were deposited on pretreated PE. These thin flexible films show antibacterial properties under light. $\mathrm{TiO}_{2}$ sputtered, RF-plasma pretreated $\mathrm{PE}$ led to a fast bacterial loss of viability compared to non-pretreated PE. The reversible hydrophobic to hydrophilic kinetics conversion of $\mathrm{PE}-\mathrm{TiO}_{2}$ under simulated solar irradiation was followed by contact angle. The innovative $\mathrm{PE}-\mathrm{TiO}_{2}$ films described in this study may have high potential for practical applications.

\section{Acknowledgements}

We thank the Swiss National Science Foundation (SNF) for the financial support of the Project: Preparation, testing and characterization of innovative intravascular catheters inactivating bacteria by contact (oligodynamic effect) and the COST Actions MP1101, MP1106 and TD 0906 for interactive discussions during the course of this study.

\section{References}

1 W. Tung and W. Daoud, J. Mater. Chem., 2011, 21, 7858-7865.

2 L. Zhang, R. Dillert, D. Bahnemann and M. Vormoor, Energy Environ. Sci., 2012, 5, 7491-7507.

3 A. Bozzi, T. Yuranova and J. Kiwi, J. Photochem. Photobiol., A, 2005, 172, 27-35.

4 A. Torres, C. Ruales, C. Pulgarin, C. Aimable, P. Bowen, V. Sarria and J. Kiwi, ACS Appl. Mater. Interfaces, 2010, 2, 2547-2552.

5 T. Yuranova, A. Rincon, D. Laub and J. Kiwi, Catal. Today, 2007, 121, 109-116.
6 C. Chan, T. Ko and H. Hiroaka, Surf. Sci. Rep., 1996, 24, 1-22.

7 J. Kassanen, M. Suvanto and T. Pakkanen, J. Appl. Polym. Sci., 2007, 119, 12.

8 M. I. Mejia, J. Marin, G. Restrepo, C. Pulgarin, E. Mielczarski, J. Mielczarski, Y. Arroyo, J.-C. Lavanchy and J. Kiwi, Appl. Catal., $B, 2009$, 91, 481-488.

9 K. Sarakinos, J. Alami and D. Konstantinidis, Surf. Coat. Technol., 2010, 204, 1661-1684.

10 P. J. Kelly and R. D. Arnell, Vacuum, 2000, 56, 159-172.

11 K. Page, M. Wilson and I. P. Parkin, J. Mater. Chem., 2009, 19, 3819-3831.

12 H. A. Foster, P. Sheel, D. W. Sheel, P. Evans, S. Varghese, N. Rutschke and J. H. M. Yates, J. Photochem. Photobiol., A, 2010, 216, 283-289.

13 H. M. Yates, L. A. Brook, I. B. Ditta, P. Evans, A. H. Foster, D. W. Sheel and A. J. Steel, J. Photochem. Photobiol., A, 2008, 197, 197-205.

14 A. Fujishima, T. Rao and D. Tryk, J. Photochem. Photobiol., C, 2000, 1, 1.

15 J. Houska, S. Mraz and J. M. Schneider, J. Appl. Phys., 2012, 112, 073527.

16 K. Tennakone, C. Tilikaratne and I. Kottegoda, J. Photochem. Photobiol., A, 1995, 87, 177.

17 B. Ohtani, S. Adzuma, S. Nishimoto and T. Kayiga, Polym. Degrad. Stab., 1992, 235, 53-61.

18 C. Gunawan, W. Teoh, P. Marquis, J. Lifla and R. Amal, Small, 2009, 5, 341-349.

19 D. Naumann, C. Schultz, A. Sabich, M. Kasrowsky and H. Labishinsi, J. Mol. Struct., 1989, 214, 213-222.

20 J. Kiwi and V. Nadtochenko, J. Phys. Chem. B, 2004, 108, 17675-16781.

21 V. Nadtochenko, C. Pulgarin, P. Bowen and J. Kiwi, J. Photochem. Photobiol., A, 2006, 181, 363-369. 